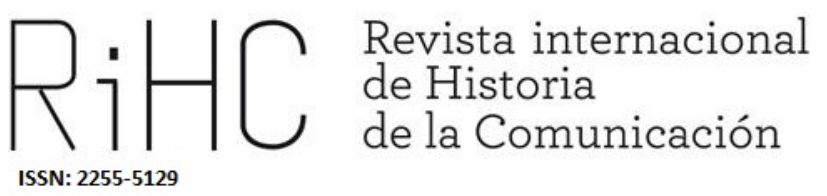

\title{
EL MENSUARIO VIDA CANARIA (1928-1929): ÓRGANO DE LA ASOCIACIÓN CANARIA DE MONTEVIDEO
}

The Vida Canaria monthly (1928-1929): organ of the Canary Association of Montevideo

DOI: http://dx.doi.org/10.12795/RiHC.2019.i12.11

Recibido: 23/02/2019

Aceptado: $15 / 05 / 2019$

Publicado:15/06/2019

Oleguer Vall Font

Universitat de Barcelona, España

oleguervallifont@gmail.com

ORCID (D): 0000-0003-4282-1037 
Resumen: La revista Vida Canaria fue una elaborada publicación de cuidada presentación, órgano de expresión de una entidad fundada a raíz del encuentro de la célebre intelectual canaria Mercedes Pinto con la comunidad isleña de la capital uruguaya, dónde se articularán de forma compleja los escenarios ideológicos presentes en ambas orillas a través de sus editoriales y artículos de opinión. Resumidamente tenemos que mientras en Uruguay se está produciendo un proceso lento y paulatino de pérdida de hegemonía del Batllismo: una ideología pequeñoburguesa reformista, inclusiva y que "coqueteaba" incluso con las doctrinas anarquistas y socialistas, en España quienes están perdiendo esta hegemonía son precisamente los sectores conservadores adscritos a la Dictadura de Miguel Primo de Rivera por la acción de un conglomerado ideológico fundamentalmente republicano-anarquista.

Palabras clave: Vida Canaria, Batllismo, Anarquismo, Primoriverismo

Abstract: The magazine Vida Canaria was an elaborate publication of careful presentation and an organ of expression of an entity founded as a result of the meeting of the famous Canarian intellectual Mercedes Pinto with the island community of the Uruguayan capital. In a complex manner the periodical depicted the different existing ideological scenarios through its editorials and opinion articles. The political panorama of the time could be summed up as follows: while in Uruguay there is a slow and gradual process of loss of Batllismo hegemony: an ideology of reformist, inclusive, petit bourgeois character which even "flirted" with the anarchist and socialist doctrines, in Spain those who are losing their hegemony are precisely the conservative sectors attached to the Dictatorship of Miguel Primo de Rivera for the action of a fundamentally republicananarchist ideological conglomerate.

Key words: Vida Canaria, Batllism, Anarchism, Primoriverism

\section{Estado de la cuestión y metodología:}

La emigración canaria a Uruguay es el capítulo menos estudiado del periplo migratorio isleño en América. Existen, sin embargo, algunos artículos dispersos de investigadores que provienen, en su mayoría, de la república rioplatense ${ }^{1}$. Como datos importantes hay que destacar que la ciudad de Montevideo fue poblada en su origen con 50 familias canarias, cuyas primeras 13 llegaron en el año 1727. Es importante señalar también que la migración procedente del archipiélago que se produce, sobre todo a partir de la emancipación americana, tiene en Uruguay una pauta diferente a la de Venezuela y Cuba: Esta no procederá de las islas canarias occidentales (Tenerife, La Gomera, La

\footnotetext{
${ }^{1}$ Entre ellos destaca Nelson Martinez Díaz con obras tan importantes como Inmigración canaria y expansión de la frontera agrícola en Uruguay-1830-1880 donde se explica con detalle el papel de la emigración isleña en la implementación de una economía agrícola cerealera en la República (como consecuencia histórica de este poblamiento, aún hoy día se conoce como "canarios" a los habitantes del Departamento de Canelones).
} 
Palma y El Hierro) sino de las orientales periféricas (Lanzarote y Fuerteventura). Esto es debido a factores externos (el Uruguay demandaba agricultores cerealeros, siendo conejeros y majoreros especialistas en ello) e internos (en un primer momento, la crisis de la barrilla y el vino que se arrastraba desde finales del siglo XVIII y, posteriormente, la crisis del sector cerealero por la desprotección que la reforma de 1900, del Decreto de Puertos Francos de 1852, sumió a las dos islas).

Como consecuencia de lo que decíamos al principio, el mensuario Vida Canaria solo es mencionado en la obra Canarias-Uruguay-Canarias: El Papel de los emigrantes canarios en el tejido empresarial de Canarias y Uruguay de Fernando Carnero Lorenzo y Juan Sebastián Nuez Yánez y en un trabajo inédito de la antropóloga uruguaya, descendiente de canarios, Isabel Barreto Messano Asociacionismo Canario en el Uruguay limitándose a escuetas descripciones sobre la entidad responsable del mensuario, en el primer caso, y en la transcripción de artículos y exposición de las diferentes juntas directivas en el segundo.

A fin de adentrarme en las características ideológicas de esta publicación, perspectiva inexplorada por los autores mencionados, se ha procedido a utilizar una metodología hermenéutica (análisis del discurso) contextualizada en un estudio del Zeitgeist (espíritu de época) en ambas orillas, centrándome en los aspectos intelectuales y políticos, todo ello bajo un enfoque marxista que concibe las formas culturales, políticas e ideológicas como parte de una "superestructura", epifenómeno de una determinada posición de clase en la sociedad.

\section{Introducción}

El mensuario Vida Canaria aparece, entonces, en un momento en que las fuerzas progresistas del Batllismo ${ }^{2}$ uruguayo están declinando y el catolicismo prefascista español de Miguel Primo de Rivera está sucumbiendo por la acción de los intelectuales republicanos y el movimiento obrero anarquista. Esta peculiar situación "intersticial", donde cada una es el espejo invertido de la otra, se reflejará de forma clara en dos períodos ideológicamente diferenciados en la revista: a) el que va del n우 de Vida Canaria, de enero de 1928, hasta el no8 de Agosto-Septiembre del mismo año con una tendencia ideológica, que podríamos resumir aquí, entre el batllismo y el anarquismo y

\footnotetext{
${ }^{2}$ Corriente interna liberal progresista del Partido Colorado Uruguayo encabezada por el Presidente de la República José Batlle y Ordoñez (1856-1929) que se basó en la implementación de ciertos monopolios estatales y leyes de avanzada. Mantuvo, al igual que el radicalismo de Hipolito Irigoyen en Argentina, una relación ambivalente con el movimiento obrero caracterizada por la combinación de persuasión y represión.
} 
b) el que va del no9 de Vida Canaria, de Octubre-Noviembre de 1928, hasta el no9 (bis) ${ }^{3}$ de febrero del año siguiente con una tendencia ideológica, que podríamos resumir aquí, netamente primoriverista y, por lo tanto, de tendencia católico-fascista. Además, la entidad editora aparece en el primer período como Asociación Canaria de Montevideo y en el segundo como Asociación Canaria del Uruguay si bien en la personería jurídica no se modifica el nombre en ningún caso.

La apariencia estética de la revista cambia también con el viraje ideológico: Así los números que van del 1 al 8 aparecen presentados con una elaborada portada encabezada por las letras, mayúsculas y en posición de semicírculo, Vida Canaria: inmediatamente debajo aparece el escudo del archipiélago, coronado y sustentado por dos canes (estos dos elementos aparecen bajo un fondo de color). Por otra parte, en el centro aparece una ilustración paisajística de las islas (distinta en cada número) en un fondo donde se distinguen dos palmeras y la imagen del que supongo el volcán tinerfeño Teide rodeado de nubes.

En cambio, los números 9 y 9 (bis) aparecen presentados con una portada gruesa y de diseño austero y monocolor (grana y beige respectivamente), donde debajo de las letras subrayadas de imprenta Vida Canaria aparece la leyenda Órgano de la Asociación Canaria en el Uruguay. El 9 (bis), por otra parte, cambia ligeramente el diseño pues el subrayado del título es cruzado por una línea vertical que recuerda a una cruz cristiana. La antropóloga uruguaya, de ascendencia canaria, Isabel Barreto Messano recoge en su obra inédita Asociacionismo Canario en el Uruguay (Barreto Messano, 1997: 57-58) usando la información dispersa que aparece en los distintos números de Vida Canaria, las cuatro Juntas Directivas con las que contó la asociación editora (1927, 1928, 1929 y 1932). Los cambios en la nómina de socios que se producen de 1928 a 1929 adquieren, a la luz de este enfoque ideológico centrado en la revista, una nueva dimensión pues observamos que tres de los socios que no figuran en la nueva Junta de 1929 tampoco figuran ya en la nómina de socios de la entidad: Manuel J. Sauri, Felipe Pérez Hernández y José Maria Pacheco ${ }^{4}$.

Sin duda alguna la ausencia más relevante es la de Manuel J. Sauri quien era nada menos que el "Presidente de redacción" de Vida Canaria, como aparece reseñado en el número 7 de la revista, y un asiduo colaborador con artículos de opinión y pequeñas obras literarias. Su verbo liberal encendido, en ocasiones cercano al anarquismo en su defensa de la Ayuda Mutua como se verá, hace sospechar su expulsión o desafiliación voluntaria ante el viraje primoriverista de la asociación. Esta hipótesis puede venir reforzada por la afirmación del historiador canario Manuel Hernández González de que entre los socios de esta entidad conviene reseñar la presencia entre ellos de dirigentes obreros de

\footnotetext{
3 Los dos números aparecen como "nำ".

${ }^{4}$ VIDA CANARIA, Archivo de Revistas de la Biblioteca Nacional de la República, Ubicación 3365, no9. Montevideo, octubre-noviembre de 1928, p. 17 a 20.
} 
ideología anarquista (Hernández González, 2008: 108). Si bien no señala de donde obtiene dicha información su opinión se asemeja a la que me manifestó Barreto Messano en una conversación informal en julio de 2010.

Pero esto adquiere aún mayor significatividad si tenemos en cuenta un aspecto pasado por alto del proceso electoral que encumbró a la Junta Directiva de 1928: En el número 7 de Vida Canaria en el artículo referente a las Actividades de la Asociación Canaria de Montevideo se informa que en las votaciones de la Asamblea de socios salió victoriosa la lista que llevaba el nombre de Non Plus Ultra ${ }^{5}$. La historiadora Rosa Cal Martínez, de la Universidad Complutense de Madrid, nos recuerda la existencia, entre mayo de 1926 a marzo de 1929, de la Agencia de Propaganda Hispano-Americana "Plus Ultra" creada por el Régimen de Primo de Rivera para contrarrestar la propaganda que la oposición hacía desde su exilio, francés y latinoamericano fundamentalmente. El nombre proviene del hidroavión militar que realizó por primera vez un vuelo entre España y América tripulado por el Comandante Ramón Franco y tres españoles más. (Cal Martínez, 1995: 177-178).

Nos recuerda otro historiador, David Marcilhacy, como el Régimen quiso atribuirse este mérito para, en el plano de la política interna, consolidar la unidad nacional y su legitimidad exaltando los valores hispánicos y, en cuanto a la política exterior, provocar la admiración de América y recuperar así la influencia de España en este continente, pues se emulaba con la "epopeya colombina". Así el intelectual primoriverista José María Pemán, en una conferencia dada en 1927 ante la Real Sociedad Geográfica, calificó la gesta de "estridencia sublime" necesaria para despertar el expansionismo espiritual de España. La creación, por Real Decreto del 3 de abril de 1926, de la "Medalla del Plus Ultra" fue acompañada de una argumentación en la que, según Marcilhacy, el nacionalismo español reclamaba para sí la condición de universalidad entroncando con sus raíces cristianas y el mítico período de Carlos V (Marcilhacy, 2006: 226-228).

Así es fácil suponer que el nombre de la lista victoriosa respondía al sector contrario al primoriverismo y los ideales que él encarnaba. Figuraba en ella además la misma fundadora, Mercedes Pinto, que como se conoce se había exiliado en Uruguay, en septiembre de 1924, a raíz de una conferencia en el Ateneo de Madrid titulada "El divorcio como medida higiénica" lo que le ganó las amenazas y enemistad del mismo Primo de Rivera, quien estaba en relación estrecha con la Santa Sede (Martinez y Cagnasso, 2007: 26-29). Así es aún más sorprendente como en la Junta Directiva de 1929 (cuyo proceso eleccionario para más "inri" no aparece detallado en Vida Canaria ${ }^{6}$ )

\footnotetext{
${ }^{5}$ Vida Canaria, Archivo de Revistas de la Biblioteca Nacional de la República, Ubicación 3365, nำ7 julio de 1928. Montevideo, p. 8.

${ }^{6}$ En efecto mientras la elección en 1928 de la lista Non Plus Ultra aparece detallada en la reseña Actividades de la Asociación Canaria de Montevideo del no7 (Páginas 5 a 9), el proceso eleccionario de la nueva Junta de 1929 no aparece descrito en ninguna parte, apareciendo la nueva Comisión Directiva en la página 17 del $n$ ㅇ. Hay en el $n$ 요 de la revista un artículo que, en un ejercicio de intuición, porque le
} 
figuran todos los miembros que estaban en la Non Plus Ultra de 1928 menos ocho, a pesar de que el enfoque ideológico de la revista ha experimentado un cambio radical de posiciones progresistas al primoriverismo.

El más destacado es José Valido Romero que sigue como Presidente y otros como Víctor Acuña pasa de la vice-presidencia a un puesto de vocal. Pero lo más sorprendente quizás es que si bien Mercedes Pinto no se mantiene como bibliotecaria (la substituye Agustín Morales) sigue en la nómina de socios y lo que me parece más intrigante: sigue colaborando con la revista. Así incluso en un discurso pronunciado para la celebración del "Día de la Raza", que aparece transcrito en el no9 de Vida Canaria, afirma que:

El inmigrante de una patria conmovida por las revoluciones continuadas, el que sabe de hambre y de miseria popular; el que ha sentido el látigo de la esclavitud, el casco del militarismo, la espuela de la opresión (...) no podrá jamás (...) recordar a su país con la inmensa ternura, con el amor apetecido y sin límites, con que podemos recordar a nuestra patria nosotros, los hijos de Canarias (...) Donde todo el mundo tiene un pedazo de pan (...) donde hay paz, siempre hay paz (...) donde nadie se muere de frio, ni de hambre (...) Por eso, nosotros, los inmigrantes canarios no hemos venido a tierra de América echados por las guerras ni por las revoluciones, por la miseria ni por la maldad, sino por ansia de aventuras, por anhelo de un engrandecer y de mejorar que está en nosotros desde que nacimos $(\ldots)^{7}$.

A simple vista, estas afirmaciones no pueden ser más que tomadas con estupor teniendo en cuenta, por una parte, que desde principios del siglo XX se venían arrastrando en Canarias problemas agudos de vivienda, de largas jornadas de trabajo, de carestía de la vida, para la cual era frecuente recurrir a la prostitución para salvarse del hambre o al alcoholismo como forma de evasión. El proceso migratorio, por otra parte, siguió siendo la forma más eficaz que ha tenido históricamente el archipiélago para aliviar la tensión social sin modificar las estructuras que la provocaban. En este período se producirá un importante desplazamiento hacia Cuba pues Canarias estaba en plena "crisis de la cochinilla", liquen tintóreo que será substituido por colorantes artificiales afectando gravemente una economía de monocultivos muy dependiente de los mercados internacionales. (Hernández González, 2005: 98)

Intentaré a lo largo de este artículo responder entonces a los dilemas que se han planteado respecto la supuesta presencia de dirigentes obreros anarquistas, que

\footnotetext{
faltan las hojas 8 y 9, entendemos que pertenece al ex presidente Cándido López Trujillo pues se trata de unas palabras en un homenaje al presidente anterior y donde se cita como nuevo presidente a José Valido Romero. VIDA CANARIA, Archivo de Revistas de la Biblioteca Nacional de la República, Ubicación 3365, no7 y 8 . Montevideo, 1928.

${ }^{7}$ VIDA CANARIA, Archivo de Revistas de la Biblioteca Nacional de la República, Ubicación 3365, nำ9 octubre-noviembre de 1928, Montevideo, p. 15.
} 
colaboren en la revista de la entidad o que figuren en la nómina de socios, y a que se puede deber la permanencia de los liberales progresistas de la lista Non Plus Ultra ante el nuevo rumbo primoriverista tomado por la entidad a través de su órgano de expresión, objeto de estudio en estas páginas. Pero antes se verá en detalle los elementos ideológicos que conectan la revista con el contexto de su época a través de sus editoriales y artículos de opinión.

\section{Las editoriales del primer período: Entre el liberalismo progresista y la ayuda mutua anarquista}

\subsection{Primera Editorial}

En la primera editorial titulada "Propósitos de esta revista" se realiza una apasionada defensa de los motivos que impulsan la edición de Vida Canaria: Encontramos ideas como progresión ascendente o la concepción de que todo lo incipiente se desarrolla y todo lo pequeño crece y se robustece referidas al carácter inicial que tienen los proyectos de la asociación así como los mejores augurios para un futuro, que se desea esplendoroso y lleno de actividades ${ }^{8}$. La concepción "ascendente" del progreso, como señala Robert Nisbet, tiene un remoto origen en la Antigua Grecia en la figura de Hesiodo (Circa 700 A.C) como también afirma que es exclusiva del pensamiento político occidental la idea de que la historia de la humanidad consiste en una lucha "paso a paso" por perfeccionarse.

Ya en el siglo XVIII, Emanuel Kant, en una breve obra titulada Idea de una historia universal desde un punto de vista cosmopolita, defiende cierta concepción "determinista" del progreso cuando afirma que: todas las aptitudes implantadas en una criatura por la naturaleza están destinadas a desarrollarse por completo (Nisbet, 1986: 13). Para el filósofo alemán esto se relaciona con la voluntad que no es otra cosa que una "facultas animae", es decir, lo que nos permite actuar, una "razón práctica" que se desarrolla en relación antagonista con otros hombres, pero sólo en el sentido de que esta tiende al establecimiento de un orden regulado por la ley (Fuentes, 2007: 78). Esta noción de una voluntad subordinada a la razón como causa del progreso aparece en esta

\footnotetext{
${ }^{8}$ VIDA CANARIA, Archivo de Revistas de la Biblioteca Nacional de la República, Ubicación 3365, no1 enero de 1928, p. 3.
} 
misma editorial cuando se afirma, unos renglones más abajo, que el desarrollo de la asociación es cuestión exclusiva de voluntad ${ }^{9}$

Lo segundo queda claro en la siguiente cita que se refiere a los valores de la asociación en relación a la procedencia insular, así esta entidad afirma defender La bandera del progreso de todos los canarios sin dispersiones localistas que a nada sano conducen ${ }^{10}$. Recordemos que Kant afirmaba el "mutuo antagonismo" como motor del progreso humano pues este tendía hacia un orden, esta idea a su vez fue recogida por Krause con su idea de un ser armónico integrado en las instituciones sociales. Se ve así como en esta cita se condena la "dispersión" si bien no el antagonismo propiamente: Entonces si bien el "insularismo" siempre ha sido un condicionante de la cultura canaria, también es cierto que se ha observado como los emigrantes canarios en los países de destino tendieron a "fusionar" los elementos culturales de las distintas islas en varias festividades, que a veces adoptaban el carácter de "competiciones". ${ }^{11}$ (Ascanio Sánchez, 2002: 207-224)

Finalmente se señala que en la implementación de todos los proyectos, encaminados al engrandecimiento de la asociación, no tendrán más cortapisas que las impuestas por las normas constitucionales del Uruguay, de amplísima facultad ${ }^{12}$. El politólogo Daniel Chasquetti nos recuerda que la Constitución vigente por entonces era la de 1918 que fue resultado de un acuerdo interpartidario y que consagró que los ciudadanos, individual y colectivamente, pudieran formular sus preferencias libremente, manifestarlas públicamente ante la ciudadanía y el gobierno y la garantía de recibir igualdad de trato institucional debido a estas, representando la institucionalización de una práctica política que se venía fomentando anteriormente (Chasquetti, 2003: 70).

\subsection{Segunda editorial}

En la editorial titulada "Cartas Vistas" aparece una queja incipiente al escaso interés que parece manifestar la comunidad canaria montevideana por asociarse a la entidad, si bien se afirma que se trata de una problemática general a las entidades que los residentes de un país (refiriéndose, sin duda, a los inmigrantes) constituyen. Esta editorial manifiesta su perplejidad haciendo, otra vez, adhesión a la cultura y sistema político de la

\footnotetext{
${ }^{9}$ Ibídem.

${ }^{10}$ Ibídem.

${ }^{11}$ La antropóloga canaria Carmen Ascanio señala, para el caso de Venezuela, como durante la "Fiesta del emigrante", creada en 1990, se unificaba la cultura entre las islas y entre los canarios y los venezolanos: iban todos los canarios a los actos aunque se mostraran patronas de islas concretas, así se hacían "invitaciones" a la presencia de los símbolos de otras islas.

${ }^{12}$ VIDA CANARIA, Archivo de Revistas de la Biblioteca Nacional de la República, Ubicación 3365, no1 enero de 1928, p. 3.
} 
República. Así se afirma: una nación americana que de todos, nativos y extranjeros cuida por igual (...) y una prodigiosa saturación de cultura poliforme, humana y constructiva a la vez, son características de notable relieve al más sencillo golpe de vista ${ }^{13}$.

El análisis que Arturo Ariel Betancourt (Betancourt, 1997: 46-47) realiza de las políticas migratorias de la época, destaca el "impulso batllista" por suavizar los efectos socialmente negativos de la Ley inmigratoria de 1890 , de carácter restrictivo. En un período, que el autor sitúa entre 1907 y 1928, destaca la Ley del 12 de julio de 1911, que establecía el anticipo de pasajes, y otra de 1928 en que se destinaban sumas concretas para el alojamiento de estos y que desembocaría en la construcción del llamado "Hotel de Inmigrantes". Estas disposiciones, si bien el autor señala su carácter paradójico por darse en la última fase de la inmigración masiva, debieron contribuir a la superación de las condiciones de exclusión inicial que permitieron a los inmigrantes insertarse en la sociedad uruguaya.

\subsection{Tercera editorial}

Con el título "Marcha ascendente" no aporta nueva información de relevancia para profundizar en la ideología de la Asociación Canaria, pues ya se ha analizado el uso análogo de progresión ascendente en la primera editorial a través de la filosofia de Kant. La editorial continúa su tono liberal y optimista, su fomento de la hermandad entre todos los canarios, además de seguir alabando las instituciones e idiosincrasia uruguayas. Si es de destacar la afirmación de que Pronto nuestra asociación contará con doscientos socios ${ }^{14}$, lo que permite observar el progreso desde los 80 socios iniciales que asistieron a la Asamblea General Ordinaria del 30 de Julio de 1927 (Carnero Lorenzo y Nuez Yanez, 2006: 274), así como la introducción de algunas temáticas que se desarrollaran con mayor extensión en la siguiente editorial: las ventajas del cooperativismo y la ayuda mutua.

\subsection{Cuarta editorial}

Efectivamente, el siguiente editorial, "Puntos prácticos", empieza con la afirmación de que "las nociones de toda "cooperativa" son la expresión empírica del gran principio práctico de la Ayuda Mutua, así como la realización de la teoría de esas nociones en un organismo cooperativo en marcha es una forma concreta de la polimorfología

\footnotetext{
${ }^{13}$ VIDA CANARIA, Archivo de Revistas de la Biblioteca Nacional de la República, Ubicación 3365, no2 febrero de 1928, p. 3.

${ }^{14}$ VIDA CANARIA, Archivo de Revistas de la Biblioteca Nacional de la República, Ubicación 3365, no3 marzo de 1928, p. 3.
} 
mutual” ${ }^{15}$. Esta cita del principio que guía cualquier cooperativa y el hecho de que aparezca escrita en mayúscula podría sugerir que se está refiriendo al desarrollo teórico anarquista de esta idea en Pedro Kropotkin (1842-1921). Por otra parte, el militante libertario Juan Carlos Mechoso nos recuerda que las ideas mutualistas del también anarquista Pierre-Joseph Proudhon (1809-1865) fueron recogidas por los inmigrantes españoles (vinculados al incipiente obrerismo libertario) desde finales del siglo XIX para atender a sus necesidades básicas (Mechoso, 2011: 38).

Siguiendo las afirmaciones de Manuel Hernández González e Isabel Barreto Messano se debería establecer entonces una relación directa entre la defensa editorial de esta Ayuda Mutua y la presencia de dirigentes obreros anarquistas en la asociación. Aun así no se conoce la fuente que permite afirmar esto y se tiene la evidencia de que las ideas de mutualismo no fueron solamente defendidas en Uruguay y Canarias por el movimiento anarquista sino por otros actores como el cooperativismo agrario (Bertullo, Isola, Castro y Silveira, 2004: 3-9) y, lo que es más importante, estas ideas ya en la década de los veinte podría darse el caso que hubieran sido importadas a sectores de avanzada del batllismo o incluso desprendidos de él.

A fin de cuestionar estas afirmaciones he realizado una investigación de la prensa anarquista, que se publicaba en este período, encontrando en la Biblioteca Nacional las siguientes publicaciones: El Hombre, Solidaridad, La Batalla, El Obrero Gráfico y El Obrero Panadero. El Hombre, que evoluciona del apoyo irrestricto a los planteamientos anarcosindicalistas "ortodoxos" de la Federación Obrera Regional Uruguaya (F.O.R.U.), en contra de los "anarcodictadores" de la Unión Sindical Uruguaya (U.S.U.) ${ }^{16}$ (López D’alessandro, 1992: 247-283) a posiciones más de conciliación entre ambas tendencias, es una publicación ácrata bastante ecléctica donde también aparece representada la variante anarco individualista básicamente a través de un tal Walter Ruiz. En esta publicación se ha encontrado a una única persona que podría haber sido socio de la Asociación Canaria de Montevideo, pues el nombre del articulista Antonio L. de Alarcón en El Hombre podría estar haciendo referencia al socio Antonio López, que en la nómina de socios de la entidad ${ }^{17}$ aparece como residente en Barcelona y Egipto del barrio obrero del Cerro.

\footnotetext{
${ }^{15}$ VIDA CANARIA, Archivo de Revistas de la Biblioteca Nacional de la República, Ubicación 3365, no4 abril de 1928, p. 1.

${ }^{16}$ Esta polémica, que fue resultado del impacto de la Revolución Bolchevique (1917) sobre el movimiento libertario en el país, tuvo su eje pivotal alrededor de la aceptación o no de la idea de "dictadura del proletariado" que emanaba del ejemplo ruso. Mientras los primeros rechazaban de plano la asunción de este concepto los segundos proponían manejarlo "como anarquistas", es decir, entenderlo no como dictadura "de un partido" sino "de una clase" agrupada fundamentalmente en los sindicatos.

${ }^{17}$ VIDA CANARIA, Archivo de Revistas de la Biblioteca Nacional de la República, Ubicación 3365, no9. Montevideo, octubre-noviembre de 1928, p. 17.
} 
De Antonio L. de Alarcón también encontramos un artículo anterior en El Hombre llamado "La necedad de los hombres", del 10 de abril de 1924, que hay que interpretar como una defensa de la ética individual anarquista. En él se afirman cosas como el hecho de que:

Cuando los hombres creen demasiado en sus propios méritos, y viven en la seguridad de que hay quienes adoran su persona, están a un paso de la idiotez (...) Poco debe importar al hombre que lo elogien o que lo critiquen, si hay conciencia, si hay pensamiento, si hay sobre todo independencia (...) El problema capital de la humanidad es el problema de la libertad. Todo lo demás es necedad, torpe manía de los hombres, cuando no maldad manifiesta. ${ }^{18}$

Esta mezcla, contradictoria pero dinámica, de aspectos socialistas e individualistas también aparece en La Moral Anarquista de Piotr Kropotkin, en su forma anarcocomunista, cuando afirma a la empatía como fundamento de la solidaridad humana. (Kropotkin, 1898: 5).

Por otra parte, ni en Solidaridad, el órgano oficioso de la Federación Obrera Regional Uruguaya (F.O.R.U.) cuyos ejemplares se conservan des del 15 de julio de 1912, ni en el periódico La Batalla, muy próximo a los postulados de la Unión Sindical Uruguaya (U.S.U) cuyos ejemplares se conservan de julio de 1915 a diciembre de 1927, he podido encontrar ninguna coincidencia entre la nómina de socios de la entidad canaria y algún articulista. No es el caso de El Obrero Gráfico, afín a la U.S.U., donde aparece una pequeñísima coincidencia de un nombre (muy común, por otra parte) como es José Fernández que figura tanto en un artículo referente a las nuevas comisiones sindicales, resultado del proceso eleccionario interno, y en la nómina de socios de la Asociación Canaria de Montevideo. ${ }^{19}$

Finalmente, en El Obrero Panadero tampoco he podido encontrar ninguna coincidencia con la nómina de socios de la entidad canaria. Soslayando el hecho de que los supuestos "dirigentes obreros anarquistas" de la asociación pudieran estar firmando con seudónimos, hecho que tampoco era infrecuente pero que nos llevaría al pantanoso terreno de la especulación, se debe afirmar contundentemente que no, no hay la "fuerte presencia de dirigentes obreros anarquistas" en esta entidad de la que nos habla Manuel Hernández González en varias de sus obras: Esta afirmación, creo, se debe a cierta incomprensión del complejo contexto ideológico uruguayo de la época pues, según me manifestó personalmente Isabel Barreto Messano, se fundamentan en la defensa del mutualismo que hace la Asociación y que según conversaciones que mantuvo con el

\footnotetext{
${ }^{18}$ EL HOMBRE - Revista Anarquista - Año VIII, 1ạ Época, Montevideo, no 265, 10 de abril de 1924, p.7. Archivo de Periódicos de la Biblioteca Nacional, Ubicación 32/4.

${ }^{19}$ EL OBRERO GRÁFICO - Publicación mensual del sindicato de artes gráficas (Adherido a la Unión Sindical Uruguaya) Montevideo, noviembre de 1925. Página 3. Ubicación: 29/1 (microfilms) y Vida Canaria, Archivo de Revistas de la Biblioteca Nacional de la República, Ubicación 3365, no4 abril de 1928, p. 19.
} 
historiador Carlos Zubillaga se trata de la única asociación de inmigrantes españoles del período donde se hace una defensa tan clara y expresa de esta doctrina.

\subsection{Quinta editorial}

En la quinta editorial titulada "En el yunque", aparte de continuarse con la defensa de la salvadora ancla de la Ayuda Mútua aparece una agria queja de sumo interés por cuanto puede aproximarnos al análisis de las contradicciones de clase no ya en el seno de la Asociación Canaria sino en el conjunto de la colectividad canaria en Montevideo. La editorial afirma entonces que "en esta ciudad se encuentran (...) canarios y oriundos de Canarias tan bien forrados de buena intención, que el día menos pensado nos han de sorprender en la grata noticia de alguna dádiva a la Asociación Canaria; pero no de las chicas y triviales sino de aquellas que marcan jalón en la historia de una institución y constituyen la piedra angular de su definitivo engrandecimiento". ${ }^{20}$

Este maravilloso sarcasmo permite introducir dos temas interesantes: uno haría referencia al valor y génesis de este en la cultura uruguaya/canaria y otro a la "batalla de ideas" en el seno del mismo batllismo. Según Luis Alberto Spilzinger (que diferencia las siguientes formas del "humor"), a diferencia de la ironía, que es una "burla disimulada", el sarcasmo es una "burla sangrienta": pero ambas pretenden, en mayor o menor grado, colocar al interlocutor en una situación de "inferioridad o minusvalía" que puede llevar al revanchismo (Spilzinger, 2002: 588). Debe entonces enfocarse el análisis en los efectos "catárticos" que tiene para el emisor del mensaje que permiten aliviar una situación de "injusticia humillante" experimentada. Está claro, entonces, que la Asociación Canaria con esta crítica mordaz, si bien podía buscar "conscientemente" las dádivas a que hace referencia, inconscientemente buscaba simplemente liberarse de dicha "injusticia humillante".

Además, a esto hay que sumar la constatación por parte de los emigrantes canarios asociados que su labor podría verse truncada por problemas económicos, defraudando así las expectativas que se habían puesto en la Asociación Canaria: las dificultades económicas que atravesaba la entidad en relación al optimismo de sus proyectos (mutualismo, periodismo, conmemoraciones festivas) debió ser importante, de ahí que aparezca también en varios números las siguientes leyendas:

El amor hacia la Asociación Canaria debe demostrarse con obras. ${ }^{21}$

\footnotetext{
${ }^{20}$ VIDA CANARIA, Archivo de Revistas de la Biblioteca Nacional de la República, Ubicación 3365, no5 mayo de 1928, p. 3. (el subrayado es mío).

${ }^{21}$ VIDA CANARIA, Archivo de Revistas de la Biblioteca Nacional de la República, Ubicación 3365, no1 enero de 1928, p. 13.
} 
"Es deber de todo canario trabajar entusiastamente por el engrandecimiento de la Asociación, (...) Protéjala subscribiéndose y haciéndola conocer a sus amistades, CONSOCIO: Contribuya al sostenimiento y progreso de esta revista haciendo subscriptores para ella. ${ }^{22}$

Nosotros lo esperamos a Ud. y ¿Usted que espera? Venga a nuestra sede social, asociándose y subscribiéndose a Vida Canaria, Cuando una revista nos trae recuerdos y noticias del lugar donde vimos la luz (...) Surge entonces un deseo de protegerla, prestigiarla, difundirla. Haga Ud. estas cosas, querido isleño!, Avisar en una Revista de determinada colectividad es sembrar dentro de sus filas clientes de los productos, artes, industrias ${ }^{23}$.

Querido isleño: Las mejores conquistas son las que se realizan en los dominios de la fraternidad. Las bellezas de las obras de los hombres en el mundo se deben al concurso y cooperación de todos, Los avisos que ven la luz en esta Revista son leídos por más de 3000 lectores $^{24}$.

La transcripción literal de estos mensajes tiene un motivo evidente: Se puede observar la evolución progresiva en los números 3 y 4, pues la intensidad de los ruegos se acentúa con el profuso uso de exclamaciones e interrogaciones (además de que dichos textos ocupan más espacio), seguramente la muestra más evidente es el último mensaje del número 4 donde se apela directamente a los posibles beneficios resultantes de anunciarse "para los clientes". A partir del número 5, dónde se produce el sarcasmo en la editorial "En el Yunque" que se ha visto, disminuyen ostensiblemente los mensajes y vuelven a tener un carácter de ruego o de indirecta. Así se puede observar como el "estallido sarcástico" va acompañado de cierto sentimiento "de culpa" por la "explosión emocional": prueba evidente de que el alivio de las tensiones es el motivo principal del sarcasmo y no apelar al interlocutor.

\subsection{Sexta editorial}

En la editorial titulada "Ideas, Planes y Proyectos" se hace una defensa, expresa y apasionada, del "idealismo" que nos vuelve a la reflexión acerca de las bases filosóficas de la entidad. Algunos ejemplos sobresalientes son:

\footnotetext{
${ }^{22}$ VIDA CANARIA, Archivo de Revistas de la Biblioteca Nacional de la República, Ubicación 3365, no3 marzo de 1928 , p. 1,5 y 9.

${ }^{23}$ VIDA CANARIA, Archivo de Revistas de la Biblioteca Nacional de la República, Ubicación 3365, nำ abril de 1928. Páginas 1,3 y 5.

${ }^{24}$ VIDA CANARIA, Archivo de Revistas de la Biblioteca Nacional de la República, Ubicación 3365, no5 mayo de 1928 , pp. 1 y 11.
} 
La luz de las ideas posee en su seno la potencia fermentativa para la transformación progresiva de todas las cosas (...) Todo ha procedido de la idea (...) el fuego de la verdad y el bien (...) realidad y verdad son la misma cosa (...) iBueno, Bello y Útil definición adecuativa del concepto filosófico de lo verdadero! (...) libertad integral del pensamiento (... $)^{25}$.

Como esta temática recuerda a la de la primera editorial, me aproximaré a ella desde otra obra clásica de la historia de la filosofía uruguaya: Espiritualismo y Positivismo en el Uruguay de Arturo Ardao: En ella se hace un repaso histórico a la polémica entre "idea" y "materia" en la conformación de la institucionalidad universitaria en el país.

Así a las concepciones ideológicas del batllismo se llega a través de un proceso errático donde espiritualismo ecléctico (primigenia mezcla de empirismo inglés e idealismo alemán) y positivismo (síntesis del racionalismo francés con el empirismo inglés) se fusionan (Ardao, 1950: 19-68). Esta compleja síntesis parece, en esta editorial, decantarse por las concepciones del idealismo kantiano y hegeliano: ya decía Kant que la realidad no se puede aprehender directamente sino solo a través de la idea que distinguimos y nos hacemos de ella, defiende entonces una génesis idealista donde "verdad" y "bien" son parte de un continuum no directamente cognoscible pero que, precisamente por eso, orienta al ser humano hacia su continua perfección.

\subsection{Séptima editorial}

En la séptima revista en lugar de una editorial se encuentra un poema del poeta canario Luis Doreste Silva, participante de la llamada "Tertulia del Café Suizo" ya bien entrado el siglo XX (Moreno y Morrero, 2006: 6), “Arrorró”, basado en la canción de cuna popular canaria del mismo nombre, selecciono de las estrofas del poema:

Escuchad, al varón de la cuna/ donde el niño con fiebre se agita/a la madre dormirse cantando/con su voz de ternura infinita/ (...) Está grave el hijito del alma/ella palpa su sien abrasada/ iduerme! ¡Duerme! le dice y le arrulla con su voz de cariño impregnada/ iOh que dulce arrorró de la infancia!/ iOh bendito arrorró de mi tierra!/ el que expresa el cariño más grande que en el pecho de madre se encierra! $!^{26}$

Puede resultar sorprendente, a simple vista, este giro poético respecto a las editoriales de encendido entusiasmo y crítica hacia los "insolidarios" y "bien forrados" paisanos

\footnotetext{
${ }^{25}$ VIDA CANARIA, Archivo de Revistas de la Biblioteca Nacional de la República, Ubicación 3365, no6 junio de 1928 , p. 1.

${ }^{26}$ VIDA CANARIA, Archivo de Revistas de la Biblioteca Nacional de la República, Ubicación 3365, no7 julio de 1928. Página 1.
} 
canarios residentes. Considero que se debe interpretar como un mecanismo psicológico amoroso "de compensación" ante el más que probable espíritu revanchista que provocó en los bien forrados la editorial "En el Yunque" del número 5.

\subsection{Octava editorial}

En la octava revista tampoco aparece editorial y, en su lugar, se transcribe un poema del intelectual canario emigrado a Cuba Félix Duarte titulado "La Cumbre" del que seleccionaré los siguientes pasajes:

Aunque te hieran los ásperos quijanos del camino; aunque te auguren los pobres de espíritu, el más rotundo de los fracasos, en tu empresa admirable y salvadora; aunque nunca llegues a lograr la finalidad que constantemente persigues, continua tu viaje hacia la cumbre (...) Todos anhelamos llegar a una cumbre resplandeciente de gloria y de amor y, sin embargo, cuán pocos saben que tienen una cumbre de oro en sus corazones cuyo valor no lo comprenden por la sed que les devora! (...) Desde la cumbre se contempla más hermoso el cielo (...) Por algo los viejos portuarios se ocultaban en ellas para pensar en Dios (...) iLa Cumbre, la Cumbre! Joven o anciano, príncipe o mendigo, labriego o soñador, apóstol o maestro (...). ${ }^{27}$

Hipotéticamente considero que este poema viene a colación del hecho de constatar, por parte de los redactores de Vida Canaria, que su estrategia amorosa "de compensación" no obtuvo los resultados esperados de los bien forrados, aun así de la lectura de estos pasajes seleccionados se pueden distinguir dos niveles diferenciados de interlocución: uno que es autorreferencial (haciendo referencia a la voluntad de proseguir con las actividades de la Asociación Canaria pues parece evidente la analogía entre el uso de La Cumbre de Félix Duarte y la editorial "Marcha Ascendente" de la tercera editorial y su tono liberal y optimista) y el otro que se dirige, una vez más, a los bien forrados anteponiendo su corazón áureo a su insaciabilidad (considero que hay que entenderlo en el sentido de una apelación a sus "buenos sentimientos" en oposición a una "sed" que hipotetizo que hay que interpretar como "de capitales", es decir una "sed ahorrativa" que les impediría el altruismo hacia la entidad).

\footnotetext{
${ }^{27}$ VIDA CANARIA - Revista Mensual Órgano de la Asociación Canaria- Archivo de Revistas de la Biblioteca Nacional de la República, Ubicación 3365, no8 agosto-septiembre 1928, p. 1.
} 


\section{Las editoriales y artículos del segundo período: La ideología protofascista del primorriverismo}

\section{1. primera revista}

En la primera revista, de este nuevo período ideológico, en "El Marqués de Estella en Canarias" se realiza una crónica periodística de la llegada de Miguel Primo de Rivera al archipiélago. Cabe destacar el tono justificativo de la dictadura cuando se afirma que “(...) lo de Dictador sea un término impropio, al decir de Baldomero Argente, puesto que asume sus poderes bajo el control del Rey" ${ }^{28}$. A decir verdad, este hecho no le exime de ser tal como no eximiría a Benito Mussolini por el hecho de que el rey Víctor Manuel le encargara formar gobierno. Esta frase, pronunciada por uno de los principales defensores del liberalismo georgista en España, nos muestra la conversión de sectores políticos de avanzada al protofascismo primoriverista, de la misma manera que, sorprendentemente, ocurre con la entidad objeto de estudio.

Otro de los pasajes a destacar es la afirmación atribuida al Dictador de que "(...) las Canarias no necesitan para sus productos más mercado que el peninsular" ${ }^{29}$ hecho que significa el inicio de una política autárquica en economía, tendiente a deshacer el librecambismo del Decreto de Puertos Francos de 1852, y que suponemos no debía agradar demasiado a los miembros de la colectividad inglesa, residente en la isla de Gran Canaria, que "depositó sendos ramos de flores, en el carruajes que lo conducía" ${ }^{30}$ pues esta nación era la principal beneficiada históricamente de la política librecambista del archipiélago, convirtiendo este gesto en un acto hipócrita y motivado por una obligada cortesía ante el principal mandatario del país.

La crónica periodística va seguida del artículo "El centenario pleito de la aldea de San Nicolás" donde se elogia a la Dictadura por la resolución de un conflicto entre unos aldeanos y unos propietarios de un marquesado en la isla de Gran Canaria. El tono ideológico del escrito parece ir en la línea antioligárquica de la que presumía el primoriverismo aunque esta, en varias ocasiones, demostrara ser más ficticia que real, pues como nos recuerda el historiador israelí Shlomo Ben-Ami refiriéndose a la composición del partido del régimen "Unión Patriótica”: “...los ejemplos de las provincias predominantemente agrarias, donde el caciquismo se las arregló para

\footnotetext{
${ }^{28}$ VIDA CANARIA - Revista Mensual Órgano de la Asociación Canaria no9 Año I octubre-noviembre de 1928, p. 1. Archivo de Revistas de la Biblioteca Nacional de la República. Ubicación 3365.

${ }^{29}$ Ibídem, p. 2.

${ }^{30}$ Ibídem, p. 3.
} 
adueñarse de la UP y convertirla en el 'viejo régimen disfrazado'”' (Ben-Ami, 1984: 141). Por ejemplo, en las Canarias Orientales el partido estaba compuesto de antiguos correligionarios del desaparecido cacique grancanario Fernando León y Castillo ${ }^{31}$.

Para finalizar el análisis de la primera revista de este nuevo período señalar la inclusión de un poema sobre la derrota del Almirante británico Horacio Nelson en su intento de conquista del archipiélago canario en julio de 1797 donde se le define como déspota y verdugo $^{32}$ y donde en referencia a la nación española se dice "Nación tenaz como ninguna que, tras centurias de obstinadas lides, lanzó la Media Luna al otro lado de la mar Alcídes" ${ }^{33}$. Recordar que las proclamas antibritánicas son un elemento consubstancial al nacionalismo reaccionario español que hunde sus raíces en hechos históricos como la participación de esta nación en el proceso independentista hispanoamericano, además las referencias a la expulsión de los musulmanes durante el reinado de los Reyes Católicos van en la línea de la importancia atribuida por José Pemartín (intelectual orgánico del régimen) a este período como cristalizador de la nacionalidad española ligando esta, íntimamente, a la religiosidad. ${ }^{34}$

\subsection{Segunda revista}

El segundo número de la revista empieza con un artículo de J. F. Padrón, a modo de editorial, titulado "El Emigrante Canario en América" donde se queja lacónicamente de la falta de implicación asociativa de la comunidad canaria en las repúblicas del Plata, a diferencia de lo que ocurre, siempre según el autor, en Cuba y Venezuela. No me detendré a analizar el porqué de un hecho difícil de demostrar, y que escapa a mis pretensiones modestas en cuanto a ámbito geográfico de estudio, pues el mismo autor señala que la menor presencia de isleños en las primeras no le sirve pues "no dependería

\footnotetext{
${ }^{31}$ Fernando León y Castillo (Telde, 30 de noviembre de 1842-Biarritz, 12 de mayo de 1918) nació en el seno de una familia acaudalada y de gran prestigio en Gran Canaria. Consideraba que la monarquía constitucional era la forma de gobierno menos imperfecta. Con el triunfo de "La Gloriosa" de 1868 empieza a ocupar cargos de responsabilidad. Organizó el Partido Liberal Canario afín a Mateo Sagasta. Defendió una línea reformista en cuanto a las posesiones coloniales españolas como Cuba, tendiente a igualar en derechos a los peninsulares, pero sin cuestionar la soberanía sobre estas. Se le recuerda, entre otros hechos, por promover la construcción del Puerto de La Luz en Las Palmas.

32 VIDA CANARIA - Revista Mensual Órgano de la Asociación Canaria no9 Año I octubre-noviembre de 1928, p. 14. Archivo de Revistas de la Biblioteca Nacional de la República. Ubicación 3365.

${ }^{33}$ Ibídem, p.14.

${ }^{34}$ Llama la atención, además, que este poema no se incluyera en el número de julio del anterior período ideológico de la Asociación Canaria pues lo haría coincidir con el aniversario de los hechos. Quizás sea un hecho casual o quizás debamos pensar que viene a colación de la nueva orientación ideológica de la entidad.
} 
el éxito de una intentona similar a la cantidad sino a la calidad"35. Me interesa sobretodo aquella parte del texto que pueda ser paradigmático del viraje ideológico de la Asociación.

En relación a esto se produce una interpretación de los supuestos motivos que llevarían a la situación indicada señalando que:

al principio el canario actuaría en estas repúblicas del Plata respondiendo a sus inclinaciones naturales por luengas ascendencias recibidas, esto es franca y bonachonamente, pero que (...) a fuerza de desengaños sufridos en el trato con hombres de otras razas, acaso menos indicados a los afectos espirituales, se han amoldado al medio encerrándose en hermético egoísmo $(\ldots)^{36}$.

Estas afirmaciones denotan un evidente etnocentrismo al suponer que la afectividad mantiene algún tipo de relación con la etnicidad: posición que, en ningún momento, se defiende en el análisis del mismo problema que se produce en el primer período ideológico de la revista (Cartas Vistas del n2).

Se encuentra en esta última revista un "Resumen de la Historia del Archipiélago Canario (siglos XVI, XVII y XVIII)" del que destacaremos la crítica al feudalismo que regía en las islas de la Gomera, la Palma, Fuerteventura y Lanzarote y que condenaba a los lugareños a una vida de miseria. Ya hemos señalado que esta crítica histórica no cabe interpretarla dentro de un discurso progresista sino dentro del discurso anti oligárquico y antifeudal propio del bonapartismo protofascista de la Dictadura de Primo de Rivera. Cabe destacar también una ilustrativa frase en el artículo Santiago del Teide, referido a unas desavenencias entre un aristócrata y un pastor (que concluyen con el segundo siendo invitado a sentarse a la mesa por el primero):

La aristocracia de la cuna y del sentimiento se han fundido; y dos hombres de distintas y opuestas capas sociales, el noble y el plebeyo, en un acto cordial y espontáneo, comulgan en el mismo altar de la hidalguía ${ }^{37}$.

Expresión paradigmática, en un artículo sin firma, del carácter interclasista que todo régimen fascista (o protofascista en este caso) tiene como su principal pilar ideológico.

Para terminar también se puede apreciar cierto gusto y exaltación de la violencia, propios de la ideología que estamos analizando, en el artículo "El suceso pintoresco" que narra una discusión que llegó a las manos entre un grupo de canarios de Las Palmas por una broma protagonizada por uno de ellos al intercambiar los enseres personales

\footnotetext{
${ }^{35}$ VIDA CANARIA - Revista Mensual Órgano de la Asociación Canaria no9 Año I febrero de 1929, p. 1. Archivo de Revistas de la Biblioteca Nacional de la República. Ubicación 3365.

${ }^{36}$ Ibídem.

${ }^{37}$ Ibídem, p. 6.
} 
de los bolsillos de sus amigos mientras disfrutaban de una siesta. Reproduzco los siguientes fragmentos:

(...) campo de batalla en lucha cuerpo a cuerpo (...) mientras amenazaba con una piedra y destapaba botellas, que iba trasegando que daba gusto (...) dando tumbos (...) y dijo: - ¡Ahora pa Las Palmas en bicicleta!... y tu (al aporreado) a la Cruz Roja, en el tranvía, con mis abonos! ${ }^{38}$

Esta clase de frivolización, y hasta con un estilo narrativo que induce a pensar cierto regocijo por los hechos, de una pelea con heridos por mediación del alcohol me parece sintomático del desdén por el uso de la palabra como medio de solucionar conflictos y la exaltación de las bajas pasiones masculinas como el uso de la fuerza bruta propios de un pensamiento contrarrevolucionario acorde con la visión de España que promovían intelectuales primoriveristas como José Pemartín que, como hemos señalado anteriormente, malentendían el Superhombre nietzscheano como un simple regreso a la animalidad.

\section{Conclusiones}

Llegados a este punto restan algunas cuestiones por responder sobre el mensuario: ¿Por qué los miembros de la lista electoral de la entidad Non Plus Ultra, que interpretamos como contraria al Dictador Primo de Rivera y como opuesta a la Agencia HispanoAmericana Plus Ultra, siguen en la entidad después de su viraje ideológico? y ¿Por qué sigue en ella Mercedes Pinto intelectual conocida por sus ideas liberales y de avanzada? Estas preguntas se encuentran relacionadas con la necesidad de explicar el porqué de un viraje ideológico que, hasta el momento, sólo hemos descrito. La Dictadura de Miguel Primo de Rivera, a diferencia de lo que habían hecho los gobiernos anteriores, tuvo como objetivo relanzar las relaciones con Hispanoamérica a fin de consolidar un bloque geopolítico que, teniendo a España como nación hegemónica en su seno, le asegurara un puesto permanente en el Consejo de la Sociedad de Naciones.

En consecuencia, hubo durante su gobierno un aumento y reforma de las representaciones diplomáticas en esta región, así como se desglosó en "Política General" y "Política de América" la acción exterior que administraba el Ministerio de Estado. Se puso al frente de la Oficina de Relaciones Culturales Española (ORCE) a José Antonio Sangróniz que diseñó un plan de expansión cultural y de propaganda política que, aun así, no surtió el efecto deseado porque los planteamientos imperialistas y ultranacionalistas españoles no fueron compatibles con las ideas democrático-

\footnotetext{
${ }^{38}$ Ibídem, pp. 6-9.
} 
burguesas en que se sustentaban la mayoría de repúblicas hispanoamericanas (Carrellán, 2010: 47-48).

Pero si bien no surtió este efecto en los gobiernos del otro lado del atlántico, no se puede afirmar con la misma seguridad que no hiciera lo propio con la comunidad y entidades españolas en esta región y, entre ellas, la que es objeto de este trabajo. En la obra de Sangróniz de 1925, La expansión cultural de España en el extranjero y principalmente en Hispanoamérica, dedica especial atención a ellas entendiéndolas como uno de los soportes principales de la política exterior del gobierno. En el capítulo VIII de esta obra se cita la existencia de una Sociedad Cultural Española en Montevideo con menores medios económicos que su análoga de la capital argentina. El autor ve a ambas como modelo a exportar en el resto de la región, implicando en su creación a los diplomáticos del país.

Otro aspecto a considerar, es que Sangróniz propone una política de becas para que los estudiantes de la región puedan cursar estudios en España (Capítulo IX) así como la equivalencia de títulos académicos entre España y las naciones hispanoamericanas mediante la firma de acuerdos bilaterales (Capítulo XI) (De Sangróniz, 1925: 138-143 y 161-170). Entrar en más detalles escaparía al objetivo y extensión de este articulo así que, y siempre abriendo la posibilidad de investigaciones históricas posteriores, solo puedo afirmar que esta política necesariamente tuvo un impacto en la intelectualidad pequeñoburguesa de la Asociación Canaria que tiene que explicar a la fuerza su viraje ideológico. Como decía Marx, este sector social carece de "dinámica histórica" oscilando siempre, como una veleta, entre el proletariado y la burguesía, decantándose por aquel sector social que demuestre mayor vigorosidad política.

$Y$ es ciertamente indudable que la coalición de intereses burocrático-militares, financieros y agrarios aún en las postrimerías de la Dictadura era más fuerte que un movimiento obrero español cuya ala radical anarcosindicalista estaba siendo reprimida y cuya ala moderada socialista estaba integrada en el sistema. Esta dinámica fue sin duda reforzada por el paulatino eclipse del impulso modernizador y progresista del batllismo uruguayo que desembocaría finalmente en la presidencia y posterior dictadura de Gabriel Terra, iniciada el 31 de marzo de 1933.

\section{Fuentes primarias}

SANGRÓNIZ, JOSÉ ANTONIO DE La expansión cultural de España en el extranjero y principalmente en Hispanoamérica Editorial Hércules, Madrid-Ceuta, 1925.

EL HOMBRE - Revista Anarquista - Año VIII, 1a Época, Montevideo, no 265, 10 de abril de 1924. 
EL OBRERO GRÁFICO - Publicación mensual del sindicato de artes gráficas (Adherido a la Unión Sindical Uruguaya) Montevideo, noviembre de 1925.

VIDA CANARIA, Archivo de Revistas de la Biblioteca Nacional de la República, Ubicación 3365, Montevideo, 1928-1929. Números 1, 2, 3, 4, 5, 6, 7, 8, 9, 9 (bis).

\section{Bibliografía}

ARDAO, A. (1950) Espiritualismo y Positivismo en el Uruguay Tierra Firme - Fondo de Cultura Económica. México.

ARIEL BETANCOURT, A. (1997) Políticas migratorias en España y Uruguay en ZUBILLAGA, CARLOS Españoles en el Uruguay: características demográficas, sociales y económicas de la inmigración masiva Facultad de humanidades y Ciencias de la Educación de la Universidad de la República, Montevideo.

ASCANIO SÁNCHEZ, C. (2002) Los Canarios en Venezuela: Identidad y diferencia Centro de la Cultura Popular Canaria.

BARRETO MESSANO, I. (1997) Asociacionismo Canario en el Uruguay en Seminario "Inmigración y solidaridad étnica: el asociacionismo español en el Uruguay (texto inédito). Montevideo.

BEN-AMI, S. (1984) La dictadura de Primo de Rivera, Barcelona, p. 141 citado en PELLICER MELO, F.: Lanzarote y Fuerteventura ante la Asamblea Nacional de Primo de Rivera memoriadelanzarote.com.

BERTULLO, J.; ISOLA, G.; CASTRO, D.; SILVEIRA, M. (2004) El cooperativismo en Uruguay Universidad de La República (UdelaR), Servicio Central de Extensión y Actividades en el Medio. Montevideo.

CAL MARTÍNEZ, R. (1995) "La Agencia Plus Ultra: un instrumento de propaganda de Primo de Rivera", en Mélanges de la Casa de Velázquez. Tome 31-3, 1995.

CARNERO LORENZO, F. y NUEZ YANES, J. S. (coord.) (2006) Canarias-Uruguay-Canarias: El papel de los emigrantes canarios en el tejido empresarial de Canarias y Uruguay. Ediciones Idea, Colección "Desde América”.

CARRELLÁN RUIZ, J. L. (2010) "Las relaciones de dos regímenes autoritarios: España y Chile durante los gobiernos de Primo de Rivera e Ibañez del Campo", en Revista de Historia Social y de las Mentalidades, Departamento de Historia, Universidad de Santiago de Chile, Vol. 14. №1. 
CHASQUETTI, D. (2003) "El proceso constitucional en el Uruguay del siglo XX", en NAHUM, B. y CAETANO, G. (COORDS.) El Uruguay del siglo XX - Tomo II - La política Ediciones de la Banda Oriental. Montevideo.

FUENTES, J. J. (2007) “El problema de la voluntad en H. Arendt ¿un debate kantiano?" Revista de Filosofía de la Universidad de Chile. Santiago de Chile, № 41.

GUERRA PALMERO, R. (2005) “Estudio crítico" en LEÓN Y CASTILLO, FERNANDO Mis tiempos Ediciones Idea-Parlamento de Canarias.

HERNÁNDEZ GONZÁLEZ, M. (2008) El asociacionismo canario en América en BLANCO RODRÍGUEZ, J. A. (Ed.) El asociacionismo en la emigración española a América UNED, Zamora y Junta de Castilla y León. Salamanca.

HERNÁNDEZ GONZÁLEZ, M. (2005) La emigración canaria a América Gobierno de Canarias - Viceconsejería de Emigración y Centro de la Cultura Popular Canaria.

KROPOTKIN, $\quad$ P.: $\quad L a \quad$ Moral $\quad$ Anarquista www.edicionessimbioticas.info/IMG/pdf/la_moral_anarquista.pdf

LÓPEZ D'ALESSANDRO, F. (1992) Historia de la Izquierda Uruguaya: La Fundación del Partido Comunista y la División del Anarquismo (1919-1923). Vintén Editor. Montevideo.

MARCILHACY, D. (2006) "La "Santa María del aire": El vuelo trasatlántico del "Plus Ultra” (Palos-Buenos Aires, 1926), preludio a una reconquista espiritual de América", en Cuadernos de Historia Contemporánea de la Universidad Complutense de Madrid. Vol. 28. Madrid.

MARTínEZ, R. y CAGNASSO, A. (2007) Crónica del exilio de Mercedes Pinto en Uruguay Tomo I: Un reportaje: Artículos de prensa (1924-1925) Ediciones Bergamín. Montevideo.

MECHOSO, J. C. (2011) Acción directa anarquista: Una historia de FAU Tomo I Raíces, 1870-1940 Ediciones Recortes. Montevideo.

MORENO Y MORRERO, A. C. (2006) "Las Tertulias Intelectuales en las Islas Canarias". InfoNorte Digital.com - Información del Norte de Gran Canaria - Reportajes.

NISBET, R. (1986) "La idea de progreso", en Revista Libertas Instituto Universitario ESEADE, no5, octubre 1986. www.eseade.edu.ar. (consultada 21-4-2019)

SPILZINGER, L. A. (2002) "El uso del humor en la terapia", en Psicoanálisis APdeBA, Vol. XXIV, №3. 